\title{
Augmented Reality Sebagai Media Pembelajaran Penggambaran Ekosistem Hewan Darat Untuk Anak Tunarungu
}

\author{
Setiawan Panjirai', Bambang Robiin² \\ 1,2Program Studi Teknik Informatika, Fakultas Teknologi Industri, Universitas Ahmad Dahlan, \\ Jl.Ringroad Selatan, Kragilan,Tamanan,Kec.Banguntapan,Bantul,Daerah Istimewa Yogyakarta 55191,Indonesia \\ 1'setiawan1500018155@webmail.uad.ac.id ,2bambang.robiin@tif.uad.ac.id
}

\begin{abstract}
Tunarungu merupakan orang yang mengalami gangguan dengar sehingga kadang mengalami kesulitan dalam belajar dan membutuhkan cara khusus dan biasanya menempuh pendidikan pada sekolah luar biasa bagian B (SLBB). Guru kesulitan dalam menyampaikan pelajaran karena anak tunarungu memiliki keterbatasan dalam kosakata dan bahasa dalam berkomunikasi. Siswa kelas 6 SLB B Karnnamanohara kesulitan dalam mengenal ekosistem hewan yang ada di Indonesia. Guru juga kesulitan dalam mengajar karena dalam proses mengajar hanya menggunakan papan dan kapur. Anak-anak tersebut membutuhkan media belajar yang menarik sesuai dengan karakteristik mereka. Penelitian ini menggunakan teknologi Augmented Reality (AR) dengan metode Marker Base Tracking berbasis android karena teknologi AR dapat menggabungkan objek digital dan lingkungan dunia nyata. Pemilihan metode Marker Base Tracking karena metode ini dapat dimanfaatkan sebagai alat peraga dalam kegiatan belajar mengajar. Penelitian ini bertujuan untuk merancang aplikasi mobile penggambaran ekosistem hewan darat untuk anak-anak dengan gangguan pendengaran. Pemanfaatan alat peraga berbasis teknologi AR sangat bermanfaat dalam meningkatkan proses belajar mengajar karena teknologi AR memiliki aspek-aspek hiburan yang dapat menggugah minat peserta didik untuk memahami secara konkret mengenai materi yang disampaikan melalui representasi visual 3D dengan melibatkan interaksi pengguna dalam frame AR. Subjek pada penelitian ini adalah aplikasi penggambaran ekosistem hewan darat untuk anak-anak gangguan dengar menggunakan teknologi AR. Metode pengumpulan data dengan metode wawancara dan studi pustaka. Tahap pengembangan aplikasi meliputi analisis kebutuhan sistem, perancangan antarmuka, perancangan kartu marker, perancangan model 3D, development, implementasi dan pengujian. Penelitian ini melibatkan sebanyak sepuluh responden yaitu guru sekolah SLB Karnnamanohara. Hasil evaluasi menunjukkan bahwa skor pengujian SUS aplikasi AR sebagai media pembelajaran penggambaran ekosistem hewan darat untuk anak tunarungu adalah sebesar 71 yang berarti bahwa aplikasi AR yang dikembangkan memiliki usability yang excellent sehingga bisa diterima dengan baik nantinya oleh para pengguna.
\end{abstract}

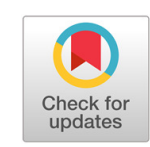

KEYWORDS

Augmented Reality Marker base tracking Ekosistem hewan darat Tunarungu

\section{Pendahuluan}

Pendidikan menjadi salah satu kebutuhan mendasar bagi manusia. Begitu pentingnya, sehingga pendidikan dapat disandingkan dengan kebutuhan akan sandang, pangan, dan papan. Bahkan di dalam undang-undang dasar negara pun, pemerintah mewajibkan rakyatnya untuk mengenyam pendidikan, sehingga pemerintah mencetuskan gerakan wajib belajar 9 tahun.

Adalah kewajiban bagi orang tua, untuk memberikan pendidikan bagi anaknya. Begitu banyaknya lembaga pendidikan yang ada, semakin membuat bingung orang tua dalam memilih lembaga pendidikan mana yang akan dipilih untuk menyekolahkan anaknya. Terutama lembaga pendidikan swasta yang 
notabene dikelola mandiri di bawah Dinas Pendidikan. Lembaga pendidikan swasta sangat bersaing ketat untuk menarik perhatian orang tua. Mereka berlomba-lomba untuk meningkatkan kualitas pendidikan sehingga memberikan kesan bagi orang tua calon peserta didik. Semakin gentarnya persaingan ini, semakin menambah bingung orang tua dalam memilih sekolah, sehingga akan menimbulkan banyak faktor dalam memilih sekolah untuk anaknya.

Untuk saat ini, pemerintah telah menerapkan sistem zonasi untuk pemilihan sekolah. Namun ini berlaku kepada sekolah negeri di bawah dinas. Adapun sekolah swasta di bawah, tidak diberlakukan sistem ini. Sekolah dipersilahkan untuk mencari siswa secara mandiri. Berdasarkan ini pula maka diperlukan adanya sebuah pertimbangan yang diberikan kepada orang tua dalam memilih sekolah berdasarkan tingkat kebutuhan orang tua [1].

Permasalahan yang sering muncul adalah kebingungan orang tua dalam menentukan Sekolah Menengah Pertama (SMP) swasta bagi anaknya. Terutama Kota Yogyakarta yang dikenal sebagai kota pelajar, memiliki banyak SMP swasta yang bisa dipilih.

Kecanggihan teknologi jaman sekarang, salah satunya adalah Sistem Pendukung Keputusan(SPK), merupakan salah satu solusi yang bisa ditawarkan [2]. SPK dapat menggunakan beberapa metode seperti Simple Additive Weighting (SAW) [3]-[9]atau menggunakan metode Weight Product [10][11].Dengan menggunakan SPK, kita akan mendapatkan bantuan pertimbangan sekolah sesuai dengan tingkat kebutuhan kita. Keluaran dari SPK bisa digunakan sebagai salah satu rekomendasi orang tua dalam memilih sekolah.

\section{Landasan Teori}

\section{A. 2.1. Sekolah Menengah Pertama[5]}

Sekolah Menengah Pertama (disingkat SMP) adalah jenjang pendidikan dasar pada pendidikan formal di Indonesia setelah lulus dari Sekolah Dasar (SD atau sederajat). Sekolah menengah pertama ditempuh dalam kurun waktu 3 tahun (kelas 7 sampai kelas 9). Pada masa penjajahan Belanda, sekolah menengah tingkat atas disebut sebagai meer uitgebreid lager onderwijs(MULO). Setelah Indonesia merdeka, MULO berubah menjadi sekolah menengah pertama (SMP) pada tanggal 13 Maret 1946 [12].

Adapun Madrasah Tsanawiyah (disingkat MTs) adalah jenjang dasar pada pendidikan formal di Indonesia, setara dengan sekolah menengah pertama, yang pengelolaannya dilakukan oleh Departemen Agama. Pendidikan madrasah tsanawiyah ditempuh dalam waktu 3 tahun, mulai dari kelas 7 sampai kelas 9. Murid kelas 9 diwajibkan mengikuti Ujian Nasional (dahulu Ebtanas) yang memengaruhi kelulusan siswa. Lulusan MTs dapat melanjutkan pendidikan ke madrasah aliyah atau sekolah menengah atas/sekolah menengah kejuruan.

Kurikulum madrasah tsanawiyah sama dengan kurikulum sekolah menengah pertama, hanya saja pada MTs terdapat porsi lebih banyak mengenai pendidikan agama Islam. Selain mengajarkan mata pelajaran sebagaimana sekolah dasar, juga ditambah dengan pelajaran-pelajaran tambahan lainnya.

\section{B. 2.2. Simple Additive Weighting (SAW)}

Salah satu metode penyelesaian masalah Multiple Attribute Decision Making (MADM) adalah dengan menggunakan metode SAW. Metode SAW sering dikenal dengan istilah metode penjumlahan terbobot. Konsep dasar metode SAW adalah mencari penjumlahan terbobot dari rating kinerja pada setiap alternatif dari semua kriteria. Metode ini banyak digunakan untuk pembuatan Sistem Pendukung Keputusan, antar alain untuk pemilihan calon peserta Olimpiade sekolah [6], penentuan penerima beasiswa, penentuan kinerja aparatur kecamatan [8], pemilihan supplier bahan [4], penentuan calon penerima raskin [5]. Penelitian yang menggunakan metode SAW juga telah dilakukan oleh [3] dan [7] untuk menentukan pemilihan sekolah.

Metode SAW memerlukan langkah perhitungan normalisasi matriks keputusan (X) sesuai persamaan 2.1. ke suatu skala yang dapat dibandingkan dengan semua rating alternatif yang ada. Metode SAW mengenal dua jenis kriteria, yaitu cost dan benefit. Cost merupakan jenis kriteria yang mengutamakan nilai 
terendah, sedangkan benefit merupakan jenis kriteria yang mengutamakan nilai tertinggi sebagai acuan pemilihan. [3]

$$
\begin{gathered}
r_{i j}= \\
\left\{\frac{x_{i j}}{\operatorname{Max} x_{i j}} \frac{\text { Min } x_{i j}}{x_{i j}} \text { jika } j \text { adalah atribut keuntungan(benefit) jika } j\right. \text { adalah atribut biaya(cost) }
\end{gathered}
$$

Keterangan :

$$
\begin{array}{ll}
\mathrm{r}_{\mathrm{ij}} & =\text { nilai rating kinerja ternormalisasi. } \\
\mathrm{x}_{\mathrm{ij}} & =\text { nilai atribut yang dimiliki dari setiap kriteria. } \\
{\text { Max } \mathrm{x}_{\mathrm{ij}}} & =\text { nilai terbesar dari setiap kriteria. } \\
{\text { Min } \mathrm{x}_{\mathrm{ij}}}_{\text {Benefit }} & =\text { nilai terkecil dari setiap kriteria. } \\
\text { Cost } & =\text { jika nilai terbesar adalah terbaik. }
\end{array}
$$

\section{Metode}

Langkah-langkah penelitian yang diambil dalam penelitian ini menerapkan metode waterfall, yaitu suatu proses pengembangan perangkat lunak secara berurutan, dimana setiap kemajuan dilihat sebagai sebuah aliran ke bawah layaknya sebuah air terjun. Tahapan yang dilalui dalam penelitian ini dapat dilihat pada gambar 1 berikut.

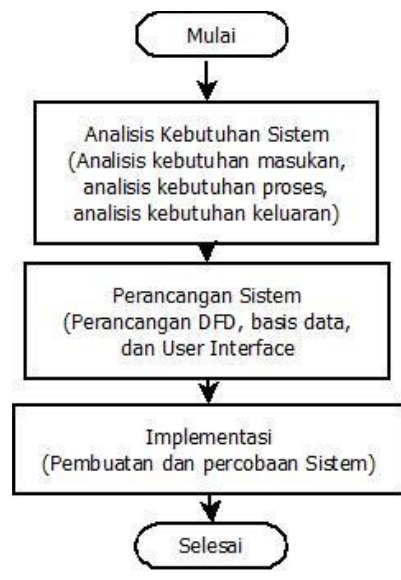

Gambar 1. Alur Penelitian

\section{Hasil dan Pembahasan}

\subsection{Penerapan Metode SAW}

Dalam proses penerapan metode SAW pada sistem pendukung keputusan pemilihan SMP swasta adalah sebagai berikut:

\subsubsection{Penentuan alternatif}

Dalam menentukan alternatif perlu dibuat matriks yang disusun berdasarkan data dari Dinas Pendidikan Kota Yogyakarta. Matriks dapat dilihat pada Tabel 1. 
Tabel 1. Matrik X Berdasarkan Data dari Dinas Pendidikan Kota Yogyakarta

\begin{tabular}{|c|c|c|c|c|}
\hline Nama Sekolah & $\begin{array}{l}\text { Biaya } \\
\text { SPP }\end{array}$ & $\begin{array}{c}\text { Dana } \\
\text { Pengembangan }\end{array}$ & Akreditasi & $\begin{array}{c}\text { Sarana } \\
\text { Prasarana }\end{array}$ \\
\hline SMP 171 & 150000 & 500000 & B & Ada \\
\hline SMP 172 & 150000 & 500000 & B & Ada \\
\hline SMP BHINNEKA TUNGGAL IKA & 100000 & 750000 & B & Ada \\
\hline SMP BOPKRI 1 & 210000 & 3500000 & A & Ada \\
\hline SMP BOPKRI 10 & 100000 & 1800000 & B & Ada \\
\hline SMP BOPKRI 2 & 180000 & 1800000 & B & Ada \\
\hline SMP BOPKRI 3 & 170000 & 1750000 & A & Ada \\
\hline SMP BOPKRI 5 & 145000 & 1600000 & A & Ada \\
\hline SMP BUDI LUHUR & 110000 & 1500000 & C & Ada \\
\hline SMP BUDYA WACANA & 160000 & 1700000 & A & Ada \\
\hline SMP GOTONG ROYONG & 135000 & 500000 & B & Ada \\
\hline SMP INSTITUT INDONESIA & 150000 & 3500000 & B & Ada \\
\hline SMP ISLAM & 110000 & 550000 & B & Ada \\
\hline SMP IT ABU BAKAR & 935000 & 17000000 & A & Ada \\
\hline SMP IT AL KHAIRAAT & 250000 & 8000000 & A & Ada \\
\hline SMP IT BINA ANAK SHOLEH & 275000 & 7500000 & B & Ada \\
\hline SMP IT MASJID SYUHADA & 430000 & 3000000 & A & Ada \\
\hline SMP JOANNES BOSCO & 190000 & 4000000 & A & Ada \\
\hline SMP KANISIUS GAYAM & 110000 & 2600000 & A & Ada \\
\hline SMP KRISTEN KALAM KUDUS & 125000 & 3000000 & A & Ada \\
\hline SMP MARIA IMMACULATA & 170000 & 3500000 & & \\
\hline MARSUDIRINI & & & A & Ada \\
\hline SMP MUHAMMADIYAH 1 & 250000 & 2500000 & A & Ada \\
\hline SMP MUHAMMADIYAH 10 & 165000 & 3000000 & A & Ada \\
\hline SMP MUHAMMADIYAH 2 & 400000 & 4800000 & A & Ada \\
\hline SMP MUHAMMADIYAH 3 & 300000 & 5000000 & A & Ada \\
\hline SMP MUHAMMADIYAH 4 & 180000 & 2500000 & A & Ada \\
\hline SMP MUHAMMADIYAH 5 & 180000 & 1000000 & A & Ada \\
\hline SMP MUHAMMADIYAH 7 & 255000 & 1000000 & A & Ada \\
\hline SMP MUHAMMADIYAH 8 & 175000 & 3750000 & A & Ada \\
\hline SMP MUHAMMADIYAH 9 & 200000 & 1500000 & A & Ada \\
\hline
\end{tabular}


Jurnal Sarjana Teknik Informatika

\begin{tabular}{|c|c|c|c|c|}
\hline SMP PANGUDI LUHUR 1 & 185000 & 2800000 & A & Ada \\
\hline SMP PEMBANGUNAN MAARIF & 100000 & 1800000 & B & Ada \\
\hline SMP PERAK & 130000 & 1000000 & C & Ada \\
\hline SMP PERINTIS & 115000 & 1000000 & B & Ada \\
\hline SMP PIRI 1 & 125000 & 2000000 & A & Ada \\
\hline SMP PIRI 2 & 125000 & 1850000 & A & Ada \\
\hline SMP STELLA DUCE 1 & 165000 & 2500000 & A & Ada \\
\hline SMP STELLA DUCE 2 & 150000 & 2750000 & A & Ada \\
\hline SMP TAMAN DEWASA IBU PAWIYATAN & 110000 & 2000000 & A & Ada \\
\hline SMP TAMAN DEWASA JETIS & 130000 & 2500000 & A & Ada \\
\hline SMP MUHAMMADIYAH 6 & 100000 & 1800000 & B & Ada \\
\hline SMP TD KUMENDAMAN & 115000 & 2000000 & B & Ada \\
\hline
\end{tabular}

\subsubsection{Penentuan bobot}

Pada contoh Gambar 2 ditentukan bobot spp: 5, pengembangan: 5, akreditasi: 5, sarana prasarana:

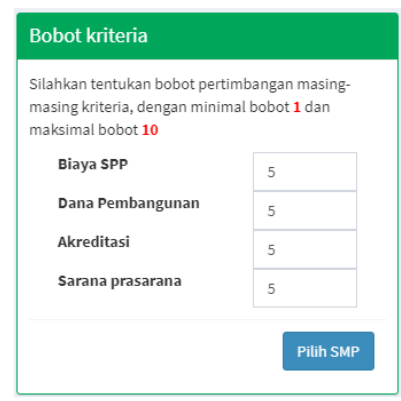

\subsubsection{Konversi nilai}

PTerlihat pada tabel 1, ada data yang yang memiliki nilai bukan angka, yaitu akreditasi dan sarana prasarana. Oleh karena itu, perlu dilakukan konversi nilai terlebih dahulu dengan aturan yang dapat dilihat pada Tabel 2 dan Tabel 3.

Tabel 2. Konversi Data Akreditasi

\begin{tabular}{ccc}
\hline No & Data & Nilai \\
\hline 1 & Akreditasi A & 5 \\
2 & Akreditasi B & 4 \\
3 & Akreditasi C & 3 \\
4 & Akreditasi D & 2 \\
5 & Akreditasi E & 1 \\
\hline
\end{tabular}

Tabel 3. Konversi Data Sarana Prasarana

No Data Nilai




\begin{tabular}{lll}
\hline 1 & Ada & 1 \\
2 & Tidak ada & 0
\end{tabular}

Sehingga data pada tabel 1 dikonversi baik data akreditasi maupun data sarana prasarana mengikuti tabel konversi yaitu tabel 2 dan tabel 3 .

\subsubsection{Normalisasi matrik $\mathrm{x}$}

Setelah dilakukan proses konversi data, maka dilakukan proses normalisasi data matrik $\mathrm{x}$ dengan memperhatikan jenis kriteria, apakah cost atau benefit. Didapatkan jenis kriteria cost: Biaya Spp dan Biaya Pengembangan, dan kriteria benefit: Akreditasi dan Sarana Prasarana.

Untuk perhitungan normalisasi matrik x setelah diketahui jenis kriteria digunakan rumus dasar 2.1:

- Kriteria biaya SPP - Cost

Nilai $\min$ SPP $=\min (150000,100000,210000)=100000$

$$
=\frac{100000}{S P P}
$$

- Kriteria biaya pengembangan - Cost

Nilai min biaya pengembangan $=\min (500000,750000,3500000)=500000$

$$
=\frac{500000}{\text { pengembangan }}
$$

- Kriteria akreditasi-Benefit

Nilai max akreditasi $\quad=\max (4,3,5)=5$

$$
=\frac{\text { akreditasi }}{5}
$$

- Kriteria sarana prasarana - Benefit

$$
\begin{aligned}
\text { Nilai max sarana prasarana } & =\max (1,1,1)=1 \\
& =\frac{\text { sarpras }}{1}
\end{aligned}
$$

Maka didapatkan nilai normalisasi pada Tabel 4.

Tabel 4. Normalisasi data matrik $\mathrm{x}$

\begin{tabular}{lcccc}
\hline \multicolumn{1}{c}{ Nama Sekolah } & $\begin{array}{c}\text { Biaya } \\
\text { SPP }\end{array}$ & $\begin{array}{c}\text { Dana } \\
\text { Pengembangan }\end{array}$ & Akreditasi & $\begin{array}{c}\text { Sarana } \\
\text { Prasarana }\end{array}$ \\
\hline SMP 17 1 & 0.67 & 1.00 & 0.8 & 1 \\
SMP 17 2 & 0.67 & 1.00 & 0.8 & 1 \\
SMP BHINNEKA TUNGGAL IKA & 1.00 & 0.67 & 0.8 & 1 \\
SMP BOPKRI 1 & 0.48 & 0.14 & 1 & 1 \\
SMP BOPKRI 10 & 1.00 & 0.28 & 0.8 & 1 \\
SMP BOPKRI 2 & 0.56 & 0.28 & 0.8 & 1 \\
SMP BOPKRI 3 & 0.59 & 0.29 & 1 & 1 \\
SMP BOPKRI 5 & 0.69 & 0.31 & 1 & 1
\end{tabular}


Jurnal Sarjana Teknik Informatika Vol. 9., No. 1, April 2021, pp. 36-45

\begin{tabular}{|c|c|c|c|c|}
\hline SMP BUDI LUHUR & 0.91 & 0.33 & 0.6 & 1 \\
\hline SMP BUDYA WACANA & 0.63 & 0.29 & 1 & 1 \\
\hline SMP GOTONG ROYONG & 0.74 & 1.00 & 0.8 & 1 \\
\hline SMP INSTITUT INDONESIA & 0.67 & 0.14 & 0.8 & 1 \\
\hline SMP ISLAM & 0.91 & 0.91 & 0.8 & 1 \\
\hline SMP IT ABU BAKAR & 0.11 & 0.03 & 1 & 1 \\
\hline SMP IT AL KHAIRAAT & 0.40 & 0.06 & 1 & 1 \\
\hline SMP IT BINA ANAK SHOLEH & 0.36 & 0.07 & 0.8 & 1 \\
\hline SMP IT MASJID SYUHADA & 0.23 & 0.17 & 1 & 1 \\
\hline SMP JOANNES BOSCO & 0.53 & 0.13 & 1 & 1 \\
\hline SMP KANISIUS GAYAM & 0.91 & 0.19 & 1 & 1 \\
\hline SMP KRISTEN KALAM KUDUS & 0.80 & 0.17 & 1 & 1 \\
\hline $\begin{array}{l}\text { SMP MARIA IMMACULATA } \\
\text { MARSUDIRINI }\end{array}$ & 0.59 & 0.14 & 1 & 1 \\
\hline SMP MUHAMMADIYAH 1 & 0.40 & 0.20 & 1 & 1 \\
\hline SMP MUHAMMADIYAH 10 & 0.61 & 0.17 & 1 & 1 \\
\hline SMP MUHAMMADIYAH 2 & 0.25 & 0.10 & 1 & 1 \\
\hline SMP MUHAMMADIYAH 3 & 0.33 & 0.10 & 1 & 1 \\
\hline SMP MUHAMMADIYAH 4 & 0.56 & 0.20 & 1 & 1 \\
\hline SMP MUHAMMADIYAH 5 & 0.56 & 0.50 & 1 & 1 \\
\hline SMP MUHAMMADIYAH 7 & 0.39 & 0.50 & 1 & 1 \\
\hline SMP MUHAMMADIYAH 8 & 0.57 & 0.13 & 1 & 1 \\
\hline SMP MUHAMMADIYAH 9 & 0.50 & 0.33 & 1 & 1 \\
\hline SMP PANGUDI LUHUR 1 & 0.54 & 0.18 & 1 & 1 \\
\hline SMP PEMBANGUNAN MAARIF & 1.00 & 0.28 & 0.8 & 1 \\
\hline SMP PERAK & 0.77 & 0.50 & 0.6 & 1 \\
\hline SMP PERINTIS & 0.87 & 0.50 & 0.8 & 1 \\
\hline SMP PIRI 1 & 0.80 & 0.25 & 1 & 1 \\
\hline SMP PIRI 2 & 0.80 & 0.27 & 1 & 1 \\
\hline SMP STELLA DUCE 1 & 0.61 & 0.20 & 1 & 1 \\
\hline SMP STELLA DUCE 2 & 0.67 & 0.18 & 1 & 1 \\
\hline SMP TAMAN DEWASA IBU PAWIYATAN & 0.91 & 0.25 & 1 & 1 \\
\hline SMP TAMAN DEWASA JETIS & 0.77 & 0.20 & 1 & 1 \\
\hline SMP MUHAMMADIYAH 6 & 1.00 & 0.28 & 0.8 & 1 \\
\hline
\end{tabular}


0.25

0.8

1

\subsubsection{Perangkingan (V)}

Pada tahap ini, dilakukan penjumlahan dari perkalian masing-masing nilai alternatif per kriteria dengan bobot yang telah ditentukan dengan menggunakan rumus pada persamaan 4.1

$$
V_{i}=\sum_{j=1}^{n} w_{j} r_{i j}
$$

Tabel 5 merupakan hasil perhitungan SAW menggunakan rumus pada persamaan 4.1.

Tabel 5. Tabel hasil perhitungan SAW

\begin{tabular}{|c|c|c|}
\hline Nama Sekolah & Nilai & Rangking \\
\hline SMP ISLAM & 18.1 & 1 \\
\hline SMP GOTONG ROYONG & 17.7 & 2 \\
\hline SMP 171 & 17.35 & 3 \\
\hline SMP 172 & 17.35 & 3 \\
\hline SMP BHINNEKA TUNGGAL IKA & 17.35 & 3 \\
\hline SMP PERINTIS & 15.85 & 6 \\
\hline SMP TAMAN DEWASA IBU PAWIYATAN & 15.8 & 7 \\
\hline SMP KANISIUS GAYAM & 15.5 & 8 \\
\hline SMP BOPKRI 10 & 15.4 & 9 \\
\hline SMP PEMBANGUNAN MAARIF & 15.4 & 9 \\
\hline SMP MUHAMMADIYAH 6 & 15.4 & 9 \\
\hline SMP PIRI 2 & 15.35 & 12 \\
\hline SMP MUHAMMADIYAH 5 & 15.3 & 13 \\
\hline SMP PIRI 1 & 15.25 & 14 \\
\hline SMP BOPKRI 5 & 15 & 15 \\
\hline SMP KRISTEN KALAM KUDUS & 14.85 & 16 \\
\hline SMP TAMAN DEWASA JETIS & 14.85 & 16 \\
\hline SMP BUDYA WACANA & 14.6 & 18 \\
\hline SMP TD KUMENDAMAN & 14.6 & 18 \\
\hline SMP MUHAMMADIYAH 7 & 14.45 & 20 \\
\hline SMP BOPKRI 3 & 14.4 & 21 \\
\hline SMP PERAK & 14.35 & 22 \\
\hline SMP STELLA DUCE 2 & 14.25 & 23 \\
\hline
\end{tabular}




\begin{tabular}{|c|c|c|}
\hline SMP BUDI LUHUR & 14.2 & 24 \\
\hline SMP MUHAMMADIYAH 9 & 14.15 & 25 \\
\hline SMP STELLA DUCE 1 & 14.05 & 26 \\
\hline SMP MUHAMMADIYAH 10 & 13.9 & 27 \\
\hline SMP MUHAMMADIYAH 4 & 13.8 & 28 \\
\hline SMP MARIA IMMACULATA MARSUDIRINI & 13.65 & 29 \\
\hline SMP PANGUDI LUHUR 1 & 13.6 & 30 \\
\hline SMP MUHAMMADIYAH 8 & 13.5 & 31 \\
\hline SMP JOANNES BOSCO & 13.3 & 32 \\
\hline SMP BOPKRI 2 & 13.2 & 33 \\
\hline SMP BOPKRI 1 & 13.1 & 34 \\
\hline SMP INSTITUT INDONESIA & 13.05 & 35 \\
\hline SMP MUHAMMADIYAH 1 & 13 & 36 \\
\hline SMP IT AL KHAIRAAT & 12.3 & 37 \\
\hline SMP MUHAMMADIYAH 3 & 12.15 & 38 \\
\hline SMP IT MASJID SYUHADA & 12 & 39 \\
\hline SMP MUHAMMADIYAH 2 & 11.75 & 40 \\
\hline SMP IT BINA ANAK SHOLEH & 11.15 & 41 \\
\hline SMP IT ABU BAKAR & 10.7 & 42 \\
\hline
\end{tabular}

\subsection{Uji validitas sistem}

Sistem diujicobakan ke 32 responden dengan menggunakan alat uji Google Form. Data nama disembunyikan untuk menjaga kerahasiaan koresponden, dan diganti dengan K01, K02, dan seterusnya. Hasil pengujian dapat dilihat pada Tabel 6.

Tabel 6. Hasil pengujian

\begin{tabular}{|c|c|c|c|c|c|}
\hline Nama & $\begin{array}{c}\text { Bobot Kriteria } \\
\text { Besar Biaya SPP } \\
\text { (Isi } 1 \text { - 10) }\end{array}$ & $\begin{array}{l}\text { Bobot Kriteria } \\
\text { Besar Biaya } \\
\text { Pengembangan } \\
\text { (Isi } 1 \text { - 10) }\end{array}$ & $\begin{array}{l}\text { Bobot Kriteria } \\
\text { Akreditasi } \\
\text { sekolah (Isi } 1 \text { - } \\
\text { 10) }\end{array}$ & $\begin{array}{l}\text { Bobot Kriteria } \\
\text { Ketersediaan } \\
\text { sarana } \\
\text { prasarana (Isi } 1 \\
\text { - 10) }\end{array}$ & $\begin{array}{c}\text { Berdasarkan dari } \\
\text { kesimpulan yang } \\
\text { ditawarkan } \\
\text { sistem, saya } \\
\text { menyatakan }\end{array}$ \\
\hline K01 & 6 & 5 & 10 & 7 & Puas \\
\hline K02 & 8 & 10 & 10 & 10 & Puas \\
\hline K03 & 8 & 8 & 10 & 10 & Puas \\
\hline K04 & 9 & 8 & 10 & 10 & Puas \\
\hline K05 & 7 & 7 & 7 & 7 & Puas \\
\hline K06 & 5 & 5 & 10 & 10 & Tidak Puas \\
\hline K07 & 9 & 9 & 9 & 9 & Puas \\
\hline K08 & 9 & 7 & 10 & 10 & Tidak Puas \\
\hline K09 & 10 & 10 & 10 & 10 & Puas \\
\hline
\end{tabular}




\begin{tabular}{|c|c|c|c|c|c|}
\hline K09 & 5 & 7 & 10 & 8 & Puas \\
\hline K10 & 8 & 8 & 9 & 9 & Puas \\
\hline K11 & 8 & 8 & 10 & 10 & Puas \\
\hline K12 & 5 & 5 & 9 & 9 & Puas \\
\hline K13 & 6 & 7 & 9 & 8 & Puas \\
\hline K14 & 5 & 5 & 10 & 9 & Puas \\
\hline K15 & 8 & 8 & 9 & 9 & Tidak Puas \\
\hline K16 & 4 & 6 & 10 & 8 & Puas \\
\hline K17 & 10 & 10 & 10 & 10 & Tidak Puas \\
\hline K18 & 4 & 7 & 9 & 8 & Puas \\
\hline K20 & 8 & 7 & 6 & 3 & Puas \\
\hline K21 & 9 & 6 & 10 & 2 & Puas \\
\hline K22 & 3 & 6 & 9 & 8 & Tidak Puas \\
\hline K23 & 10 & 10 & 9 & 9 & Puas \\
\hline K24 & 7 & 5 & 9 & 9 & Puas \\
\hline K25 & 9 & 9 & 9 & 9 & Tidak Puas \\
\hline K26 & 2 & 3 & 7 & 5 & Puas \\
\hline K27 & 8 & 6 & 10 & 8 & Puas \\
\hline K28 & 4 & 8 & 10 & 2 & Puas \\
\hline K29 & 10 & 10 & 9 & 9 & Puas \\
\hline K30 & 5 & 8 & 7 & 9 & Puas \\
\hline K31 & 8 & 9 & 9 & 6 & Tidak Puas \\
\hline K32 & 8 & 10 & 4 & 3 & Tidak Puas \\
\hline
\end{tabular}

Dari hasil pengujian kepada responden tersebut terdapat 24 responden menyatakan puas dengan rekomendasi dari sistem. Maka validitas sistem dapat dinyatakan:

$$
\frac{\text { jawaban puas }}{\text { jumlah responden }} \times 100 \%=\frac{24}{32} \times 100 \%=75 \%
$$

Sebanyak $75 \%$ respoden menyatakan puas terhadap hasil rekomendasi dari sistem yang telah dibuat.

\section{Kesimpulan}

\subsection{Kesimpulan}

Dari penelitian yang dilakukan, kesimpulan yang dapat diperoleh adalah sebagai berikut :

1. Metode SAW dapat digunakan untuk membuat sistem pendukung keputusan pemilihan SMP swasta se-Kota Yogyakarta

2. Sistem memiliki tingkat akurasi $75 \%$ dengan pengujian dari 32 responden.

\subsection{Saran}

Guna peningkatan mutu sistem, maka kami memberikan saran:

1. Alternatif dapat dipilih oleh pengguna, sehingga tidak harus semua alternatif dijadikan sebagai pilihan.

2. Ada beberapa kriteria yang dibuat bisa berinteraksi dengan pengguna, sehingga pengguna dapat mengisi kriteria yang disesuaikan dengan kondisi di lingkungan rumah masing-masing, contoh jarak sekolah 


\section{Daftar Pustaka}

[1] Kemdikbud, "Referensi Kemdikbud.” https://referensi.data.kemdikbud.go.id/ (accessed Jun. 20, 2020).

[2] S. Wiji, “Konsep Sistem Pendukung Keputusan.” Yayasan Edelweis, 2015.

[3] F. Firdausa, A. P. Wibawa, and U. Pujianto, "Model Sistem Pendukung Keputusan Pemilihan Sekolah Menggunakan Metode Saw,” SEMNASTEKNOMEDIA ONLINE, vol. 4, no. 1, p. 3, 2016.

[4] A. B. Primahudi, F. A. Suciono, and A. A. Widodo, "Sistem Pendukung Keputusan Untuk Pemilihan Karyawan Dengan Metode Simple Additive Weighting Di Pt. Herba Penawar Alwahida Indonesia," JIMP-Jurnal Inform. Merdeka Pasuruan, vol. 1, no. 2, 2016.

[5] G. Y. K. S. S. Pahu, L. R. Putri, N. Nungsiyati, and R. Renaldo, "Sistem Pendukung Keputusan Menentukan Calon Penerima Raskin Menggunakan Metode Simple Additive Weighting,” J. Teknoinfo, vol. 12, no. 2, pp. 82-86, 2018.

[6] H. Situmorang, "Sistem Pendukung Keputusan Pemilihan Calon Peserta Olimpiade Sains Tingkat Kabupaten Langkat Pada Madrasah Aliyah Negeri (Man) 2 Tanjung Pura Denganmenggunakan Metode Simple Additive Weighting (Saw), J. Times, vol. 4, no. 2, pp. 2430, 2015.

[7] Darudin, "Sistem Rekomendasi Penerimaan Beasiswa Menggunakan Metode Simple Additive Weighting (SAW) SDN 2 Kates,” 2016.

[8] M. I. Mahd, T. Susilowati, Z. Kirom, and others, "Menentukan Kinerja Pemerintahan Aparatur Kecamatan Terbaik Se-Kabupaten Tanggamus Lampung Menggunakan Metode SAW,” in Prosiding Seminar Nasional Darmajaya, 2018, vol. 1, no. 1, pp. 314-322.

[9] R. P. Simanungkalit, P. Moengin, and S. Adisuwiryo, "PERANCANGAN SISTEM PENDUKUNG KEPUTUSAN UNTUK PEMILIHAN ALTERNATIF SUPPLIERBAHAN BAKUPADA PT. TESENA INOVINDO.," in PROSIDING SEMINAR NASIONAL CENDEKIAWAN, 2017, pp. 183-190.

[10] Irma, "Sistem Pendukung Keputusan Pemilihan SMP/MTS Swasta di Kab. Kediri Menggunakan Metode Weight Product(WP),” 2016.

[11] L. Farokhah and A. Kala'lembang, "Sistem Pendukung Keputusan Pemilihan Forum Mahasiswa dengan Metode Weighted Product,” J. Ilm. Teknol. Inf. Asia, vol. 11, no. 2, pp. 179-190, 2017.

[12] Wikipedia, "Sekolah Menengah Pertama," 2020.

https://id.wikipedia.org/wiki/Sekolah_menengah_pertama (accessed Apr. 01, 2020). 